\title{
Exploration and Design of Computer Aided-Translation Teaching Course
}

\author{
Bei Du
}

School of Foreign Languages, Xi'an University,710065

\author{
Keywords: Computer-Aided translation; Course; Teaching
}

\begin{abstract}
With the development of globalization, the translation market has ushered in a great development opportunity. China's demand for translation talents has showed a geometric growth. Computer-aided translation teaching, which is a new means of translation under the information conditions, is closely related to the cultivation of high-quality translators and has received more and more attention from the society. This paper studies the exploration and design of computer-aided translation course in a bid to provide beneficial help for the development of this course.

Today's society is an era of information, in which the speed of generating and disseminating information has far exceeded the speed of our cognition. Take a simple example, a variety of nee words emerge one after another that even some words which we are originally familiar with might instantly become a new word with a brand new meaning due to the occurrence of an event or the extraction of a process.

The work of translation must closely follow the trend of the information era. In the past, we could do a good job in related work only by reading some relevant books, combing our own experience and appropriately using some translation skills. But nowadays, with the wave of information technology, those who are conservative and act blindly can hardly survive and develop in the trend of the times, and the accuracy and efficiency of translation will be greatly reduced.

The translation industry is an old and emerging industry. At present, the world is moving towards interconnection while economic, political and cultural exchanges are becoming more and more frequent worldwide, which provides an unprecedented platform for the development of translation. The increase in business activities has led to the rapid rise of the translation industry, and it is possible to say that every drip of our daily life has been inextricably linked to translation. But to some extent, the public has proposed higher requirements for the timeliness and accuracy of translation. In traditional translation, people were the main body, the efficiency was not high and the process was complicated. The computer is becoming an indispensable tool in the field of translation. Nowadays, computer-aided translation has already been included in our discipline construction system. Computer-aided translation has its unique advantages. First of all, the efficiency has been greatly improved. Secondly, the size of translation is also quite different from manual translation. Computer-aided translation is receiving more and more attention.
\end{abstract}

\section{Background of Setting Computer-Aided Translation Course}

The prosperity of economy has promoted the further development of the tide of globalization and the development of globalization also continues to boost the economy. Nowadays, as the connection between countries and people is increasingly close, language barriers and communication obstacles are increasingly obvious. At present, the lack of translation talents is an indisputable fact. With the continuous improvement of the degree of economic dependence and the increasing intensity of economic exchanges, the demand for translators is ever increasingly, which is the major economic background for setting the course computer-aided translation.

On the other hand, after these years of development and improvement, the computer industry has penetrated into all aspects of people's lives. It can be said that without the help of computers, human beings will experience a catastrophic regression, which shows how intensively and extensively computers have been involved in our life. The development of computer technologies turns aided translation into reality, which is the technical support for the course computer-aided 
translation.

Finally, the development of the Internet greatly accelerates the transmission of information. No matter where you are, you can always timely receive and send the information you want, which makes it possible that the transmission of translation information is not subject to time and geographic restrictions. In the Internet conditions, there is a fundamental change in the way information is obtained and made, and translation is no longer confined to seeking help from people around us, but to spread information to a wider range more rapidly. The combination of computers and the Internet is a change from time to time.

\section{Principles and Orientation of Computer-Aided Translation Course in China}

The principle of curriculum in China is based on the unity of practicality and teaching. Therefore, the computer-aided translation course should first follow the principle of practicality. The fundamental purpose of setting computer-aided translation course is serve for modern construction, cultivate more excellent practical translation talents, effectively enhance China's cultural exchange and trade and make the Chinese culture and global culture integrated and compatible with each other. In the computer-aided translation course, we focus on cultivating students' practical ability and urging students to learn while using the knowledge.

The principle of diversification is followed in setting computer-aided translation course. Translation is not only to reproduce the meaning of the original text, but also a cultural interpretation. Attention must be paid to a variety of cultural classes in the computer-aided translation course and organically combing cultural elements with scientific and technological elements without covering the surface with a few points. Scientific and technological means are used to assist the orderly development of translation in order to make the translation vivid, smooth, objective and appropriate.

At present, many colleges and universities have set the computer-aided translation course and classified this subject into a professional category. Thus, it can be seen that the education cycle attaches great importance to computer-aided translation course. In terms of the practical effect of carrying out this course, many colleges and universities have achieved good effect, and there might be more or less problems. After all, it has been a limited time for the establishment of this course and this course is also at a perfect development stage.

\section{Main problems in China's Computer-Aided Translation Course}

Software and hardware equipment is not perfect. The smooth development of computer-aided translation is inseparable from the investment of hardware and software investment, and the issue of capital investment is the major problems for many colleges and universities in the computer-aided translation course. Computer-aided translation requires expensive software, and a large sum of money is also required for hardware equipment. At present, many colleges and universities lack scientific research and experimental funds, and in order to put all the funds into the course, many non-key colleges and universities do not have the ability to realize this goal. Even key colleges and universities can hardly continue to strengthen investment in the same subject.

Teaching settings are unreasonable. China's computer-aided translation teaching started relatively late compared to many developed countries, did not make full investigation in the initial curriculum, and was not enough attention and research on the development of the same disciplines in foreign countries. This led to our arrangement and teaching Planning and teaching objectives require such a contradiction, in the overall layout is clearly behind the developed countries. At present, the whole society has paid more and more attention to the translators, and many well-known domestic educators have pointed out how to establish and improve the teaching system and the scientific arrangement of the curriculum are also carried out in the education sector.

The staffs' professionalism is not high. Computer-aided translation teaching requires talents with 
both computer skills and translation ability as the backbone of teaching. However, our major colleges and universities is indeed a short board in terms of teachers. This discipline requires practitioners to master the translation skills, but also familiar with the computer operation, to understand the overall mechanism of computer-aided translation technology, operating principle, but also regularly upgrade the equipment maintenance. The problem of weak teachers has seriously hindered the construction and development of disciplines. Over time, it is difficult to cultivate high-quality practical talents, the healthy development of the discipline is also out of the question.

\section{Optimize the Computer-Aided Translation Teaching Course's Module Settings}

At present, the modular curriculum design is a common practice in computer-aided translation curriculum setting. This setting of course is flexible and can be easily adjusted. In modular curriculum planning, we should distinguish between the primary and secondary, pay attention to the focus and also take into account of the entire situation.

1.Teaching module. Teaching module is the core of the entire curriculum construction, in the design of this module teaching session, we should proceed from the generalized computer-aided translation, fully consider the translation practice may encounter a variety of practical problems, in this content on the scientific construction A complete teaching content system, this system should include the following subsystems:

(1) Information Technology or Subsystem of Information Means

In high-tech conditions, recording and processing information is different from traditional mode, and information processing and recording methods with digitalization as the core have profoundly changed the way information is obtained. In computer-aided translation system, computer is the dominant processing tool, and before using computer-aided translation system, we must first have the electronic version of the source documents, convert texts and information in traditional paper media into electronic text information relying on character recognition technology. In the context of the Internet, the way to obtain text source is no longer restricted to the range of space and time. Through the Internet, we can search, download or contact the press or the author so as to get reliable electronic text information.

(2) Subsystem Input and Storage

Input technology is a bridge between text messages and computer systems. By entering the system, the information is initialized to the input source of the auxiliary translation system, as mentioned earlier, the input system has shown a variety of trends, not only rely on the keyboard as the only way. Optical and electrical information technology has opened up a lot of space for the development of entry system. Word and sentence input is the basic element of the input, in the rapid development of intelligent today, the whole sentence input technology has been very mature, conversion efficiency and accuracy have reached a very high level. What is worth mentioning here is the speech recognition system, the development of advanced speech recognition system has come to a surprising point. This not only greatly improves the performance of the input system, but also makes the input from the cumbersome complex into the fast lane.

(3) Term-base Subsystem

Translation of terms is a top priority for translation work, and its value is even greater than the translation memory that many auxiliary translation software mentions when propagating. In the actual translation work, the repetition rate of the language unit at the term level is much higher than the repetition rate of the complete translation unit. Maintenance of the term subsystem in addition to the collection, finishing, but also includes the term retrieval, optimization and maintenance of the statement library and other issues. For the collection of general terms can rely on the general office software, such as wps, word and so on. In addition, there are some small and fine specialized software can also be used to assist the terminology subsystem maintenance and management. TRADOSER terminology software is a short and pithy product, it can automatically identify the 
chaotic vocabulary in the English and Chinese language, and their rules are classified. For professional terms, you can use artificial, software, supplemented by the way to take fine and fine classification of the term.

(4) Aided Translation Application Subsystem

If the computer is the core of the auxiliary translation system, then the auxiliary translation application system is the core of the computer system. At present the application of a wide range of software systems are SDLTRADOS, WORDFAST, Google Translator tools. These software systems focus on different types, depending on the use of the environment or the use of different habits to choose.

\section{Course Assessment System}

Computer-aided translation course construction is a systematic project, on the basis of the curriculum must have a corresponding matching with the assessment system. Computer-aided translation system should be diversified and practical. At this stage, China's major colleges and universities for the computer-aided translation of the curriculum in general is a scientific objective. The theoretical part of the general use of written test, practice assessment is mainly on the machine. Computer-aided translation course is mainly to assess the ability of students with computer translation, so the curriculum assessment with a computer and translation of the dual assessment function. Computer-aided translation curriculum must establish a scientific and effective system of assessment system and assessment standards, both the emphasis on theoretical study, but also pay attention to practical results, in the score ratio as far as possible to focus on the ability to reflect the quality.

\section{Prospect of Computer-Aided Translation Course}

The advantages of computer-aided translation can be seen. In terms of the current teaching effect, we still far lag behind from foreign counterparts. In the teaching philosophy, many schools will computer-aided translation courses as elective, many of them in the last semester, which shows that the importance of our understanding of its importance should be further strengthened. The author through the investigation of the status quo of the translation industry found that the lack of translation information technology to use the ability to master, it is difficult to foothold in the translation market.

In the network conditions, many computer-aided translation software has achieved network collaboration function, the entire translation management process network, to achieve the level of translation project management network co-management. It can be said that the network is the future trend of the computer-aided translation system.

In the foreseeable future, computer-aided translation is a computer technology as the core of the network translation platform, as a teacher, both psychological and technical reserves, should do the education and teaching conditions of the reserves.

At present, China's computer-aided translation teaching has shortcomings. And I personally think the following aspects should be strengthened:

1.Depth analysis of the translation market. China is currently lack of in-depth and effective market research, and the sensitivity of translation teaching technology is not enough. Therefore, the market research for translation teaching is essential, researchers engaged in translation teaching should invest more time and energy to focus on foreign translation teaching and computer-aided translation technology, and actively explore the teaching model suited to China's national conditions.

2.Cooperate with relevant training institutions. With the continuous development of the translation industry, there have been a large number of translation companies and translation teaching institutions, these companies and institutions are mostly single-line business, such as translation companies for translation teaching institutions to provide teachers, computer-aided 
translation technology or translation software and some Translation teaching related to the books, and translation teaching institutions on the translation company is not directly exported, resulting in the domestic translation industry is not flexible enough. In view of this, the domestic translation teaching institutions should strengthen cooperation with the translation company, exchange learning, in order to achieve the prosperity of the translation industry and work. In the process of translation teaching and personnel training, the translation company should cooperate with the translation teaching institutions to achieve long-term cooperation. Translation teaching institutions can take full advantage of the translation company to provide adequate backup human resources, the translation company can save some money. At the same time, translation teaching institutions can provide some feedback on the use of software after the translation company, the translation of the teaching organization itself can also bring more orders for the translation company.

\section{Conclusion}

Economic development promotes China's foreign exchange and trade development, and in foreign exchanges and trades, we need to try our best to overcome language barriers to promote the smooth conduct of trade, which provides a rare opportunity for accelerating the development of the translation industry. With the deepening of economic globalization, there is huger and huger demand for translation, and we must improve the efficiency of translation so as to meet the increasing demand for translation. At present, with the development of science and technology, computer-aided translation has already been included into China's subject system, making important contribution to China's foreign exchange and trade.

In the process of teaching computer-aided translation, we must follow certain principles to improve translators' work ability and efficiency so as to play an important advantage of computer-aided translation so as to make the translated version has the same meaning of the original text. Meanwhile, we must develop strict computer-aided translation assessment system and assessment method so as to promote students' effective learning and make teachers timely get to know problems in the process of teaching computer-aided translation, constantly improve teachers' ability and teaching level.

In view of the current development speed, computer-aided translation technology must be applied to a more and more extensive field, which promotes the traditional translation industry to undergo enormous changes. The development trend of the translation industry is to combine traditional translation technologies with advanced computer-aided translation technologies. The majority of educators need to constantly explore and make unremitting efforts to make due contributions to the development of the translation industry.

\section{References}

[1] FAN Liyue, ZHANG Xuelu, LIU Shu. Exploration of Computer - aided Translation Course for English Majors in Colleges and Universities [J]. Northern Literature (the late version), 2017, (04): 98-100.

[2] DU Jing, LI Ying, ZHAO Hai-bing. Teaching Practice of Efficient Classroom Model in Computer Program Design Course in Military Academies [J]. Computer Education, 2017, (04): 64-67.

[3] LIU Jia. Research on Teaching Mode of Computer Assisted Industrial Design Course Group [J]. Design, 2017, (07):106-107.

[4] FAN Ling, WEI Xianhong, YIN Guodong. Exploration and Practice on Teaching Reform of Computer Aided Design Course in Chemical Engineering of Teachers College [J]. Journal of Hubei Normal University (Natural Science Edition), 2017, (01):97-100.

[5] PAN Lei, WANG Xun, ZHANG Jing. Exploration and Application of Bilingual Teaching in the Teaching of Computer Programming Language [J]. Reform and Opening Up, 2017, 
(05):115-117.

[6] LIU Fang. Practical Exploration of Classified Teaching in Computer Programming Course [J]. Tibet Science and Technology, 2017, (03):34+41.

[7] XU Jie. Research on the Teaching Reform of Computer Aided Drawing Based on the Mixed Teaching Mode [J]. Journal of Inner Mongolia University of Finance and Economics, 2017, (01):111-113.

[8] SONG Shoupeng, ZHU Feifei. Construction of Teaching Aided Framework of Computer Aided Design Course in Urban and Rural Planning [J]. Education and Teaching Forum, 2017, (08):257-258.

[9] ZHAO di. An Analysis of the Current Situation of Computer Aided Design Course and Its Reform - Taking Higher Vocational Colleges as an Example [J]. Journal of Jilin Province Economic Management Cadre College, 2017, (01):107-109.

[10]LIU Jian. Research on Course Design of Computer - aided Translation from the Perspective of Language Service Technology [J]. Journal of Nanchang Normal University, 2017, (01):67-70.

[11]HAN Bowen. A Tentative Study on the Cultivation of Russian Undergraduate Translation Professionals - Taking Heilongjiang University as an Example [J]. Research on Higher Education in Heilongjiang Province, 2017, (02):140-142.

[12]Xi Kaifu, WANG Yunxia. Exploration on the Integrated Teaching Mode of Electrical Drawing [J]. Career, 2017, (04):86-87. 